\title{
Circulating growth hormone releasing factor concentrations in normal subjects and patients with acromegaly
}

\author{
ELIZABETH S PENNY, ERICA PENMAN, JANET PRICE, LESLEY H REES, A M SOPWITH, \\ J A H WASS, N LYTRAS, G M BESSER
}

\begin{abstract}
A highly specific and sensitive radioimmunoassay was developed for measuring circulating growth hormone releasing factor (GRF) in human plasma. Before measuring immunoreactive GRF plasma samples were extracted on to Vycor glass. Immunoreactive GRF concentrations in plasma samples from 37 fasting normal subjects ranged from $<10$ to $60 \mathrm{ng} / 1$ (mean $21 \mathrm{ng} / \mathbf{1}$ ). Fasting concentrations in 76 out of 80 acromegalic subjects were within the normal range, but the remaining four patients had values of 92 to $25000 \mathrm{ng} / 1$. Of these, only the patient with the highest concentration had evidence of ectopic GRF secretion from a disseminated carcinoid tumour. Two of the others had longstanding pituitary tumours, and the fourth patient had a pituitary growth hormone (GH) secreting tumour proved by its removal and subsequent remission of acromegaly. There was no correlation between serum GH and plasma immunoreactive GRF concentrations, irrespective of whether the patients were untreated or had been given radiotherapy or dopamine agonists.

The assay should help elucidate the physiological role(s) of GRF and may also prove useful in differentiating between pituitary and hypothalamic defects in patients with acromegaly.
\end{abstract}

\footnotetext{
Department of Chemical Endocrinology, St Bartholomew's Hospital, London EC1A 7 BE

ELIZABETH S PENNY, BSC, research assistant

ERICA PENMAN, PHD, senior biochemist

JANET PRICE, PHD, senior biochemist

LESLEY H REES, MD, FRCP, professor of chemical endocrinology

Department of Endocrinology, St Bartholomew's Hospital, London EC1A 7BE

A M SOPWITH, MD, MRCP, lecturer

J A H WASS, MD, MRCP, senior lecturer

N LYTRAS, MD, research registrar

G M BESSER, MD, FRCP, professor of endocrinology

Correspondence to: Professor Lesley H Rees.
}

\section{Introduction}

Growth hormone $(\mathrm{GH})$ secretion is regulated by at least two neurohormones-somatostatin, a peptide which inhibits GH secretion, ${ }^{1}$ and a growth hormone releasing factor (GRF). Recently two groups have identified peptides with $\mathrm{GH}$ releasing activity from two pancreatic tumours, designated hpGRF. ${ }^{2} 3$ Primary structures of at least three peptides with GH releasing activity have been characterised. The predominant form in both tumours was a 40 amino acid residue peptide (hpGRF-40). In one tumour smaller amounts of hpGRF-37 and an amidated hpGRF-44 were also found. ${ }^{3}$ Two groups have now isolated the messenger ribonucleic acid encoding precursor proteins with the sequence of hpGRF and determined the sequence of the cloning deoxyribonucleic acids. ${ }^{45}$ We do not yet know whether hpGRF is normally produced in pancreatic islets or if this is an ectopic source.

Significant amounts of hpGRF-44 and hpGRF-40 have been found in human hypothalamic tissue, and chromatographic and immunohistochemical staining studies suggest that they are similar to if not identical with hpGRF. ${ }^{6}$ ' Synthetic hpGRF has been shown to stimulate GH secretion selectively in man and animals both in vivo ${ }^{8-10}$ and in vitro. ${ }^{11} 12$ The mechanism of action of GRF in releasing GH has been reported to include $\mathrm{Ca}^{-}$and cyclic adenosine monophosphate as second messenger. ${ }^{12} 13$

In order to investigate the physiological role of GRF we have developed a radioimmunoassay for GRF in human plasma. We report successful measurement of plasma GRF concentrations in normal subjects and patients with acromegaly.

\section{Subjects and methods}

Venous blood was collected from normal subjects and patients between 8 and 930 am after an overnight fast. Serum GH was assayed by radioimmunoassay as described by Forsyth et al. ${ }^{14}$ Blood for measurement of GRF was collected into lithium-heparin tubes containing $10000 \mathrm{KIU}$ aprotinin, centrifuged, and the plasma flash frozen immediately. All patients with acromegaly had the clinical features of the syndrome and failed to suppress their circulating GH normally during an oral glucose tolerance test (minimum values between 5 and $228 \mathrm{mU} / \mathrm{l})$. 


\section{RADIOIMMUNOASSAY}

An antiserum was raised against synthetic hpGRF-40 in New Zealand white rabbits. The hpGRF-40 was conjugated to bovine thyroglobulin using 1-ethyl-3-(3-dimethylaminopropyl)-carbodiimide as the coupling agent. Each animal initially received $200 \mu \mathrm{g}$ GRF emulsified with Freund's complete adjuvant in three separate subcutaneous injection sites and $100 \mu \mathrm{g}$ subsequently. Regular boosting continued until the antibody titre showed no further increase. Synthetic hpGRF-40 (Bachem) was iodinated using chloramine-T by a modification of Hunter and Greenwood's technique. ${ }^{15}$ To minimise damage to the peptide the reaction was terminated by diluting the reagents with $600 \mu 10.05 \mathrm{M}$ phosphate $(\mathrm{pH} 7.4$ ) containing $0.5 \%$ human serum albumin. The iodination products were purified on a $1.0 \times 0.5 \mathrm{~cm}$ column of octadecylsilyl silica using increasing concentrations of 1-propanol $/ 1^{\circ}$, trifluoroacetic acid (modified from Bennett et al. ${ }^{16}$ The ${ }^{125} 1$-hpGRF-40 was diluted in $50_{\%}^{\circ} 1$-propanol $/ 1 \%$ trifluoroacetic acid containing polypeptide $20 \mathrm{~g} / \mathrm{l}$, separated into aliquots and stored at $-70^{\circ} \mathrm{C}$.

The extraction of GRF from plasma was based on the method of Rees et al for adrenocorticotrophic hormone. ${ }^{17}$ Standard tubes contained $3 \mathrm{ml}$ horse serum, to which was added $8 \mathrm{ng}$ synthetic hpGRF-40 (Bachem); blanks contained $3 \mathrm{ml}$ horse serum only. Between 3 and $5 \mathrm{ml}$ of a plasma sample was used. Vycor glass $(50 \mathrm{mg}$ ) was added to each tube, which was rotated for 30 minutes. After centrifugation the supernatant was aspirated and the pellet washed with $3 \mathrm{ml}$ distilled water followed by $2 \mathrm{ml}$ molar hydrochloric acid. The GRF was eluted from the Vycor glass using $1 \mathrm{ml} 80^{\circ}$ o methanol, evaporated to dryness with oxygen free nitrogen in a sand bath at $60^{\circ} \mathrm{C}$, and the residue reconstituted in $500 \mu \mathrm{l}$ assay buffer $(0.05 \mathrm{M}$ phosphate $(\mathrm{pH} 7.4), 0.5^{\circ}$ o human serum albumin, $0.1 \%$ Triton $\mathrm{X}$, $0.05^{\circ}{ }_{0}$ mercaptoethanol). To assess assay reproducibility "low" and "high" pools (prepared by adding synthetic hpGRF-40 to horse serum) were run in each assay. The mean value of 10 aliquots of the low pool was $32 \mathrm{ng} / 1$ and the coefficient of variation $8^{\circ}{ }_{0}$. Ten aliquots of low and high pool were run in consecutive assays; mean values were $35 \mathrm{ng} / \mathrm{l}$ and $99 \mathrm{ng} / \mathrm{l}$ respectively, with corresponding coefficients of variation of $14 \%$ and $9 \%$. For each assay an unextracted standard curve was set up using doubling dilutions of hpGRF-40 (Bachem) in the range $10000-9 \mathrm{ng} / \mathrm{l}$. Each tube contained $200 \mu \mathrm{l}$ standard, which was preincubated with $50 \mu \mathrm{l}$ antiserum $\left(1 / 15000\right.$ final dilution) at $4^{\circ} \mathrm{C}$ for 24 hours before the addition of $50 \mu \mathrm{l}$ tracer. After incubation at $4^{\circ} \mathrm{C}$ for a further 24 hours the free ${ }^{125} \mathrm{I}$-hpGRF-40 was separated from the bound fraction using dextran coated charcoal, $200 \mu \mathrm{l} /$ tube. The extracted plasma samples and horse serum standards were assayed as above. Recoveries of standard hpGRF during extraction varied between 60 and $80 \%$, and all plasma samples were corrected for this and for the volume of plasma.

\section{Results}

The antiserum reacted on an approximately equimolar basis with hpGRF-40 and hpGRF-44. Cross reactivity studies using several GRF analogues showed the antiserum to be directed towards the central region of the molecule, but there was cross reactivity of less than $0.01^{\circ}{ }^{\circ}$, with a wide range of hypothalamic, pituitary, and gastrointestinal hormones including prolactin, $\mathrm{GH}$, peptide histamine isoleucine-27, and other members of the glucagon-secretin family of peptides. The affinity constant of the antiserum was $2 \times 10^{10} 1 / \mathrm{mol}$, as assessed by Scatchard analysis. The limit of detection of the assay was $10 \mathrm{ng} / \mathrm{l}$.

All the plasma samples from normal subjects and the patients with acromegaly diluted parallel to the standard curves (fig 1). The range of plasma immunoreactive GRF concentrations from 37 normal subjects (age range 21-38 years) was $<10-60 \mathrm{ng} / \mathrm{l}$, with a mean of $21 \mathrm{ng} / \mathrm{l}$ (taking undetectable concentrations as $10 \mathrm{ng} / \mathrm{l}$ for the calculation). Of the plasma samples measured from 80 acromegalic patients (aged 17-76 years), $76\left(95^{\circ}\right.$ ) gave values of immunoreactive GRF within the normal range. In the remaining four patients plasma immunoreactive GRF concentrations ranged from 92 to $25000 \mathrm{ng} / 1$ (fig 2). Simultaneously measured serum GH concentrations in the same blood samples failed to show any correlation with the immunoreactive GRF values in the 80 acromegalic patients. There were no consistent differences in immunoreactive GRF plasma concentrations dependent on whether patients were receiving bromocriptine or not or had received external radiotherapy to the pituitary (4500 rads in 25 fractions over 36 days from a linear accelerator using three fields) (fig 3). Twenty eight patients had undetectable immunoreactive GRF concentrations, and in these patients serum $\mathrm{GH}$ values ranged from
$2 \cdot 2$ to $135 \mathrm{mU} / 1$; in 12 of them $\mathrm{GH}$ concentrations exceeded $20 \mathrm{mU} / 1$. The acromegalic patients with immunoreactive GRF concentrations in the normal range had serum GH concentrations of up to $285 \mathrm{mU} / 1$.

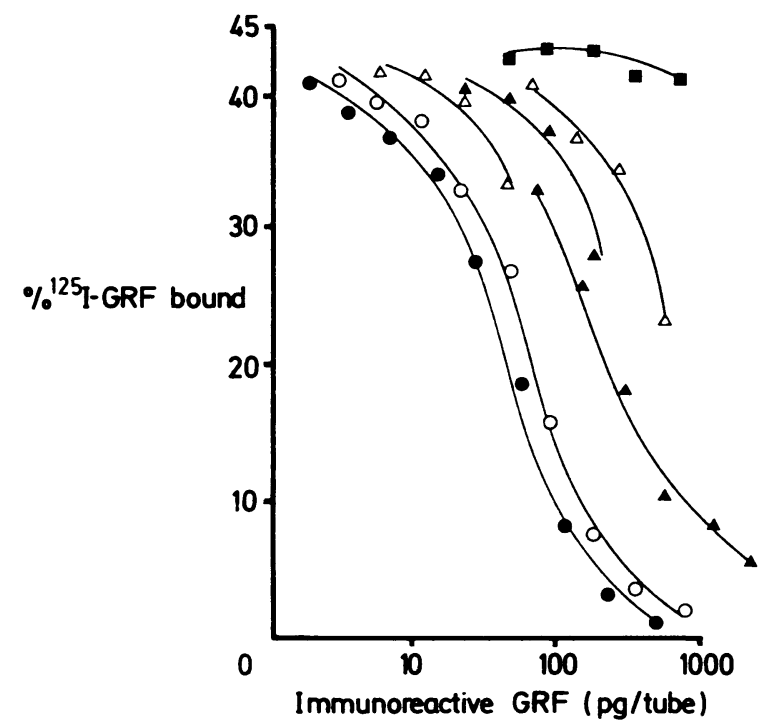

FIG 1-Parallelism of extracted immunoreactive GRF in fasting plasma samples from normal subjects $(\triangle)$ and acromegalic patients plasma samples from normal subjects $(\triangle)$ and acromegalic patients $\supset=$ extracted standard curve). Horse serum blank sample ( $\boldsymbol{\square})$ also shown.

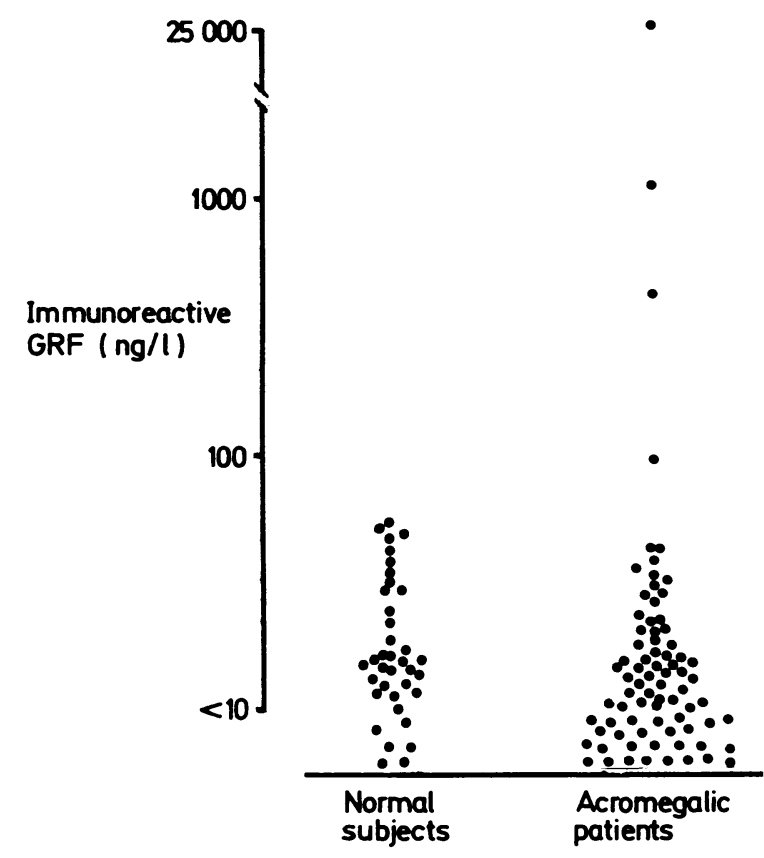

FIG 2-Plasma immunoreactive GRF concentrations in normal and acromegalic subjects (normal range $<10-60 \mathrm{ng} / \mathrm{l}$ ).

\section{Discussion}

We report the use of an assay for measuring immunoreactive GRF in human plasma. The assay is highly specific, as shown by the cross reactivity studies. Using an extraction procedure we found the assay sensitive enough $(10 \mathrm{ng} / \mathrm{l})$ to detect plasma immunoreactive GRF in both normal subjects and acromegalic patients.

Of our 80 patients with acromegaly, only four showed immunoreactive GRF concentrations above the normal range. Of these, three had no identifiable ectopic source, and indeed it was clear that they had large GH secreting pituitary tumours 


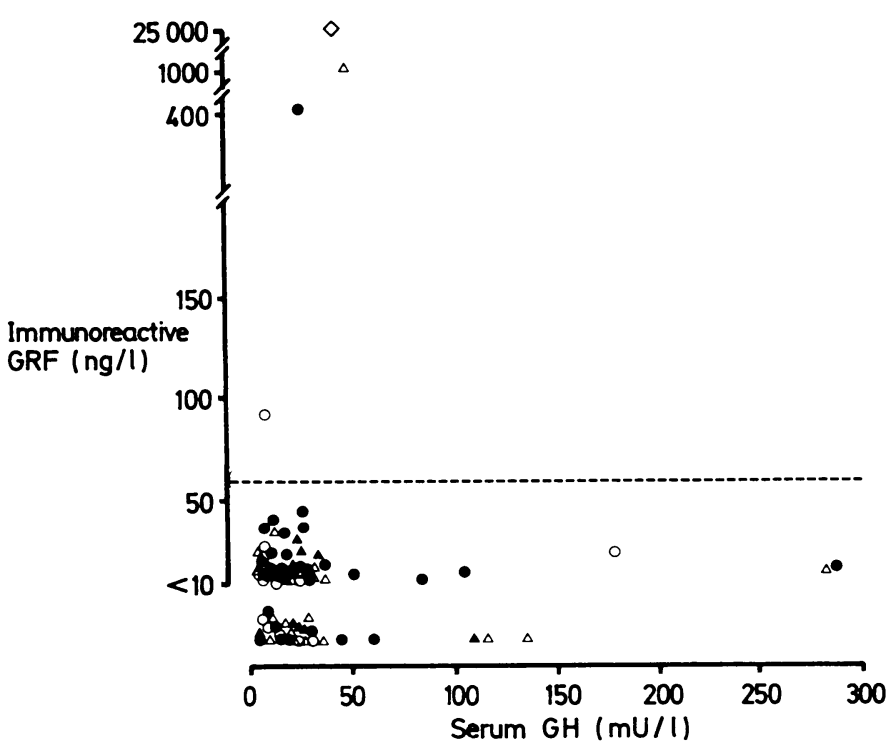

FIG 3-Immunoreactive GH and GRF concentrations in same blood samples from 80 patients with acromegaly. Open symbols indicate patients not receiving dopamine agonists (bromocriptine or pergolide); round symbols indicate those who had received radiotherapy, triangles those who had not. Diamond represents patient with disseminated GRF secreting carcinoid tumour. Interrupted line indicates upper limit of normal range for immunoreactive GRF.

(macroadenomas). In two patients acromegaly had been documented for over 10 and 25 years without evidence of any other lesion. In the third patient (plasma immunoreactive GRF value $1111 \mathrm{ng} / \mathrm{l}$ ) catheterisation of all the major veins using a previously described technique ${ }^{18}$ and extensive CT scanning of chest and abdomen failed to disclose an ectopic source for the immunoreactive GRF. She proceeded to transfrontal craniotomy for removal of a macroadenoma with a large suprasellar extension, resulting in resolution of the acromegaly and a raised circulating GH concentration. The fourth patient, however (plasma immunoreactive GRF concentration $25000 \mathrm{ng} / \mathrm{l}$ ), was known to have widely disseminated carcinoid tumour, originally diagnosed 10 years previously in the lung. After diagnosis she developed clinical and biochemical acromegaly with an enlarging fossa and hyperprolactinaemia and has been described elsewhere. ${ }^{19} \mathrm{Her}$ carcinoid tumour had been successfully controlled by repeated treatment with chemotherapeutic agents. Her greatly raised circulating concentration of immunoreactive GRF suggested that her acromegaly was due to ectopic GRF secretion from the carcinoid tumour, and this was supported by definite immunocytochemical staining of her original tumour and several metastases using an anti-GRF antiserum by an immunoperoxidase technique. Despite the raised concentrations in the other three patients they did not appear to have ectopic secretion of GRF.

The lack of correlation between plasma immunoreactive GRF and serum GH concentrations was not surprising. Negative feedback mechanisms might result in low GRF values due to raised GH concentrations-for example, in patients with pituitary tumours. Modulation of $\mathrm{GH}$ secretion by endogenous somatostatin might also contribute to this lack of correlation between GH and GRF values. Patients with hypothalamic defectsespecially in the ventromedial-arcuate region, which has been implicated in GH regulation-may show raised plasma immunoreactive GRF concentrations resulting in increased $\mathrm{GH}$ secretion. Whether sustained oversecretion of GRF may result in down regulation of the pituitary is not clear.

In view of the low concentration of hpGRF found in the human hypothalamus ${ }^{6}$ it is debatable whether GRF secreted from the hypothalamus is being detected in peripheral plasma. That we are able to measure plasma immunoreactive GRF might suggest that GRF could also be secreted from alternative sources-for example, the gut. In favour of this is both the fact that the peptide has been isolated from two pancreatic islet tumours, ${ }^{23}$ and the striking homology with the glucagonsecretin family of peptides, located normally in the pancreas and gastrointestinal tract. It has been shown, however, that intravenous administration of synthetic hpGRF in man had no effect on various enteropancreatic variables measured, including blood glucose, plasma insulin, glucagon, gastrin, and somatostatin. ${ }^{9}$

The molecular nature of the circulating immunoreactive GRF has not yet been elucidated. Our initial studies, however, have shown a single peak of immunoreactivity, coeluting with hpGRF-40 after gel filtration chromatography of a plasma sample from one acromegalic patient with very high immunoreactive plasma GRF concentrations.

This recently developed GRF radioimmunoassay will be of help in elucidating the physiological role(s) of GRF. It may also prove potentially useful in helping to differentiate between pituitary and hypothalamic defects and in identifying acromegaly associated with uncommon cases of ectopic GRF secreting tumours.

We thank members of the department of chemical endocrinology for measuring growth hormone concentrations, Dr David Coy for the gift of synthetic hpGRF-40, and Professor Nicholas Ling for the GRF analogues used in the cross reactivity studies. The work was supported by the Medical Research Council, the joint research board of St Bartholomew's Hospital, and the Peel Medical Research Trust.

\section{References}

' Brazeau P, Vale W, Burgus R, et al. Hypothalamic polypeptide that inhibits the secretion of immunoreactive pituitary growth hormone. Science 1973;178:77-9. Rivier J, Spiess J, Thorner M, Vale W. Characterisation of a growth hormonereleasing factor from a human pancreatic islet tumour. Nature $1982 ; 300: 276-8$. Guillemin R, Brazeau P, Bohlen P, Esch F, Ling N. Growth hormone-releasing
factor from a human pancreatic tumor that caused acromegaly. Science 1982;218: factor fror

4 Mayo KE, Vale W, Rivier J, Rosenfeld MG, Evans RM. Expression cloning and sequence of a cDNA encoding human growth hormone-releasing factor. Nature

Gubler U, Monahan JJ, Lomedico PT, et al. Cloning and sequence analysis of cDNA for the precursor of human growth hormone-releasing factor, somatocrinin. Proc Natl Acad Si USA 1983;80:4311-4.
cring

" Bohlen P, Brazeau P, Bloch B, Ling N, Gaillard R, Guillemin R. Human hypothalamic growth hormone releasing factor $(\mathrm{GRF})$ : evidence for two forms identical to tumor derived GRF-44NH 2 and GRF-40. Biochem Biophys Res Commun 1983;114:930-6.

Bloch B, Brazeau P, Ling N, et al. Immunohistochemical detection of growth hormone-releasing factor in brain. Nature 1983;301:607-8.

Evans WS, Borges JLC, Kaiser DL, et al. Intranasal administration of human pancreatic tumor GH-releasing factor-40 stimulates $\mathrm{GH}$ release in normal men. f Clin Endocrinol Metab 1983;57:1081-3.

Thorner MO, Spiess J, Vance ML, et al. Human pancreatic growth hormonereleasing factor selectively stimulates growth hormone secretion in man. Lancet $1983 ; \mathrm{i}: 24-8$.

Gelato MC, Pescovitz O. Cassorla F, Loriaux DL, Merriam GR. Effects of a growth hormone releasing factor in man. 7 Clin Endocrinol Metab 1983;57:674-6. cyclic AMP stimulating activity, Thorner MO. Selective growth hormone and cyclic AMP stimulating activity is present
$\mathcal{7}$ Clin Endocrinol Metab $1982 ; 55: 381-3$.

${ }^{2}$ Bilezikjian LM, Vale WW. Stimulation of adenosine 3', 5'- monophosphate production by growth hormone-releasing factor and its inhibition by somatostatin in anterior pituitary cells in vitro. Endocrinology 1983;113:1726-31.

${ }^{13}$ Brazeau P, Ling N, Esch F, Bohlen P, Mougin C, Guillemin R. Somatocrinin (growth hormone-releasing factor) in vitro bioactivity: $\mathrm{Ca}^{+}:$involvement, cAMP mediated action and additivity of effect with $\mathrm{PGE}_{2}$. Biochem Biophys Res

Commun 1982;109:588-94.
Forsyth IA, Besser GM, Edwards CRW, Francis L, Myers RP. Plasma prolactin activity in inappropriate lactation. Br Med $\mathcal{f} 1971 ;$ iii :225-7.

Hunter WM, Greenwood FC. Preparation of iodine-131 labelled human growth hormone of high specific activity. Nature 1962;194:495-6. Bennett HPJ, Hudson AM, McMartin C, Purdon GE. Use of octadecylsilyl silica 1977;168:9-13.

17 Rees LH, Cook DM, Kendall JW, et al. A radioimmunoassay for rat plasma ACTH. Endocrinology 1971;89:254-61.

${ }^{8}$ Drury PL, Ratter S, Tomlin S, et al. Experience in selective venous sampling in the diagnosis of ACTH dependent Cushing's syndrome. Br Med $\mathcal{f} 1981 ; 284$

1. Gomez-Pan A, Scanlon MF, Thorner MO, et al. Effects of somatostatin on abnormal growth hormone and prolactin secretion in patients with the carcinoid syndrome. Clin Endocrinol (Oxf) 1979;10:575-8.

(Accepted 10 May 1984) 